\title{
A concessão de uso especial para fins de moradia e a máxima da proporcionalidade
}

\author{
The granting of special use for housing and the maxim of \\ proportionality
}

\section{Mônani Menine Pereira ${ }^{1}$}

Resumo: O presente artigo aborda a concessão de uso especial para fins de moradia. Centra-se em analisar a medida de acordo com a "máxima" da proporcionalidade. Através da pesquisa doutrinária e do método indutivo, operacionalizado com as técnicas do referente, das categorias, dos conceitos operacionais e da pesquisa de fontes documentais, constatou-se que a concessão de uso especial para fins de moradia atende a máxima da proporcionalidade, especialmente quando o imóvel público dominical não cumpre a função social.

Palavras-chave: Moradia. Concessão de uso especial. Máxima da proporcionalidade. Propriedade. Função social.

\begin{abstract}
This article deals with the regulation of the "granting of special use for housing". It focuses on analyzing the measure according to the "maxim of proportionality". Through doctrinal research and the inductive method, operationalized with referent techniques, categories, operational concepts and research of documentary sources, it was verified that the "granting of special use for housing" purpose meets the maximum of proportionality, especially then the public property does not fulfill the social function.
\end{abstract}

Keywords: Housing. Granting of special use. Maxim of proportionality. Property. Social function.

\section{Introdução}

Existe necessidade de se assegurar os bens imóveis públicos, como patrimônio coletivo. É certo, porém, que da ocupação irregular e desordenada do espaço decorrem consequências sociais, econômicas e ambientais, especialmente pela costumeira falta de condições básicas de infraestrutura naqueles locais. Isso se dá, evidente, por conta da histórica e grave crise

\footnotetext{
1 Mestre em Ciência Jurídica pela Universidade do Vale do Itajaí - UNIVALI e pela Universidade de Alicante - UA/Espanha. Especialista em Curso de Pós-Graduação "Lato Sensu" em Direito Civil e Processual Civil pelo CESUSC. Especialista em Curso de Especialização em Direito e Gestão Judiciária para Magistrados pela UFSC. Graduado em Direito pela Universidade do Vale do Itajaí.
} 
habitacional que assola o país, que força um fluxo cada vez maior de pessoas a se direcionar e se concentrar nos grandes centros urbanos.

Ademais o desenvolvimento sustentável, claro, pressupõe também o planejamento e ordenamento territorial das áreas urbanas. Logo, cabe ao Poder Público solucionar as ocupações irregulares consolidadas em seus próprios imóveis, assegurando os recursos naturais, através da preservação ambiental, sem olvidar a dignidade dos ocupantes pela efetivação do direito social de moradia.

A tanto, é possível recorrer aos instrumentos gerais da Política Urbana, com destaque para a concessão de uso especial para fins de moradia prevista no $\S 1^{\circ}$ do art. 183 da Constituição Federal. Inspirado nessa medida que pode ser tomada pelo Poder Público, o presente artigo traz breve reflexão acerca da concessão de uso especial para fins moradia, a fim de demonstrar que a mesma atende a máxima da proporcionalidade, como solução das ocupações irregulares nos imóveis públicos, mesmo diante da colisão dos direitos fundamentais envolvidos.

\section{A Máxima da Proporcionalidade}

A doutrina não é acorde quanto à origem da máxima da proporcionalidade (BARROSO, 2009, p. 224 e 230), que atribui conceito idêntico à razoabilidade diferenciando apenas na nomenclatura, origem histórica e base constitucional fundamentadora, sustenta que a proporcionalidade decorre da conjugação das ideias do direito anglo-saxão (devido processo legal substantivo norte americano) e direito romano germânico (princípio do Estado de direito). Canotilho (2003, p. 266), destaca a referência primitiva ao problema da limitação do Poder Executivo, "sendo considerado como medida para as restrições administrativas da liberdade individual”. Ávila, (2003, p. 146) refuta a sinonímia entre a proporcionalidade e a razoabilidade, especificando os conteúdos e origens distintas. 
Estima-se que a proporcionalidade, com o propósito inicial de limitar os poderes dos monarcas, decorreu da evolução dos direitos e garantias individuais da pessoa humana, principiada no século XVIII com a passagem do Estado Absolutista para o Estado de Direito. Entrementes, é no direito administrativo alemão do segundo pós-guerra que a máxima da proporcionalidade inicia sua transposição para o plano constitucional, através da doutrina e da jurisprudência do Tribunal Constitucional, que posteriormente se irradiou para outros países (GUERRA FILHO, 2005, p. 262).

Também grassa dissenso doutrinário em se identificar um alicerce constitucional para a proporcionalidade na ordem jurídica brasileira. Alguns doutrinadores afirmam que a máxima da proporcionalidade decorre do Estado de Direito (GÓES, 2004, p. 77). Outros, do conteúdo essencial dos direitos fundamentais (BONAVIDES, 2006, p. 436). Existem ainda teorias mistas, como a exposta por Barros:

O princípio da proporcionalidade tem dignidade constitucional na
ordem jurídica brasileira, pois deriva da força normativa dos direitos
fundamentais, garantias materiais objetivas do Estado de Direito. É
haurido principalmente da conjugação dos artigos $1^{\circ}$, III; $3^{\circ}$, I; caput,
II, XXXV, LIV e seus $\S \S 1^{\circ}$ e $2^{\circ} ; 60, \S 4^{\circ}$, IV. Nese sentido,
complementa o princípio da reserva da lei, a ele incorporando-
se, de modo a converte-se no princípio da reserva legal proporciona.
De logo é conveniente ressaltar que a doutrina e a jurisprudência,
assim na Europa continental como no Brasil, costumam fazer
referência, igualmente, ao princípio da proporcionalidade, conceito
que em linhas gerais mantém uma relação de fungibilidade com o
princípio da razoabilidade. Salvo onde assinalado, um e outro serão
aqui empregados indistintamente. (BARROS, 1996, p. 210)

Inobstante, parece ser mais coerente, afastando a polêmica sinonímia da proporcionalidade com a razoabilidade, encontrar na garantia fundamental do devido processo legal (art. $5^{\circ}$, inc. LIV, da Constituição Federal) o embasamento constitucional para a máxima da proporcionalidade, tendo em conta a essência e destinação da mesma: preservar os direitos fundamentais. Assim se dá porque ao Estado não basta a existência de 
normas aptas a garantir os direitos fundamentais. Precisa dispor de um instrumento regulativo à vista da circunstancial colisão daqueles direitos, posto que nem sempre é possível a coexistência harmônica e simultânea do conjunto dos direitos (e garantias) fundamentais. Estima-se, aliás, que tal construção espelha a conexão da máxima da proporcionalidade com a natureza dos princípios, tal como proposta na teoria dos direitos fundamentais de Alexy (2011, p. 116-117 e 588).

Sem embargo, a aplicação da máxima da proporcionalidade pressupõe a existência de uma medida concreta destinada a realizar determinada finalidade. Sem uma relação meio-fim, sem a relação de causalidade entre o meio, a medida concreta e fim, sem esse ponto de referência, não é possível a aplicação da máxima (ÁVILA, 2003, p. 162). A máxima da proporcionalidade então analisa a possibilidade de a medida sugerida levar à realização da finalidade (adequação), de a medida ser menos restritiva entre aquelas que poderiam ser manejadas para atingir a finalidade (necessidade) e de que a finalidade justifica a restrição (proporcionalidade em sentido estrito).

Imprescindível, então, inspecionar as máximas parciais da proporcionalidade, seguindo a ordem pré-definida de submissão, já que existe entre elas uma relação de subsidiariedade. A máxima parcial da adequação (da idoneidade ou da conformidade) impõe a análise da medida (o meio) restritiva em conformidade com a finalidade perseguida. Deve-se perquirir se a medida tomada, e que restringe um direito fundamental, é adequada ao caso para fomentar ou realizar o objetivo tutelado pelo outro direito fundamental.

É a exigência de compatibilidade entre o fim pretendido e os meios enunciados para sua consecução, de sorte que a meio escolhido deve ser apto para alcançar, ou pelo menos fomentar, o fim desejado. Pondere-se que a análise da máxima parcial da adequação não é comparativa. Não se determina o meio que mais ou melhor, e com maior grau de certeza, promove o fim. Apenas examina se o meio promove o fim, de qualquer maneira, independentemente de ser o que estimula da melhor forma ou com maior grau 
de certeza. Se o meio não é capaz de realizar em nada o objetivo, se ele não contribui em nada para fomentar a finalidade, então ele é inadequado, e a medida será desproporcional e encerrar-se o exame segundo a máxima da proporcionalidade.

A máxima parcial da necessidade (da exigibilidade, da indispensabilidade, da menor ingerência ou da intervenção mínima) é um exercício comparativo. Centra-se em identificar, entre medidas adequadas a fomentar ou realizar o objetivo, a que restringe em menor intensidade o direito fundamental em colisão. A medida necessária é aquela que, sendo eficaz (adequada) para promover o fim, restringe em menor intensidade o exercício do direito fundamental em colisão. O reconhecimento da necessidade da medida, assim, pressupõe que o objeto não pode ser promovido, com a mesma intensidade, por outro meio menos restritivo. Enfim, busca-se o meio menos desvantajoso e também promove o fim escolhido.

E a máxima parcial da proporcionalidade em sentido estrito importa no próprio sopesamento entre os direitos fundamentais em jogo. É a ponderação entre a intensidade da restrição ao direito fundamental atingido e a importância da realização do direito fundamental que com ele colide e que fundamenta a adoção da medida restritiva. Alexy (2011, p. 593) afirma que a máxima da proporcionalidade em sentido estrito define a realização do princípio segundo a ponderação com os princípios colidentes, do que decorre que ela "é idêntica à lei do sopesamento, que tem a seguinte redação: Quanto maior for o grau de não-satisfação ou de afetação de um princípio, tanto maior terá que ser a importância da satisfação do outro”.

Tira-se, então, que quanto maior for a interferência no princípio colidente, mais importante deve ser a realização (adoção da medida restritiva) do outro, ponderando-se o gravame imposto a um e o benefício conferido ao outro. A desproporcionalidade da medida é deduzida a partir da constatação que os motivos que a fundamentam não têm peso suficiente para justificar a restrição ao direito atingido. 
Registre-se que a reprovação da medida pela máxima da proporcionalidade em sentido estrito não se dá apenas se a adoção daquela implicar a não realização de um direito fundamental ou que ela atinja o chamado "núcleo essencial" de um dos direitos. Basta que os motivos que fundamental a adoção da média não tenham peso suficiente para justificar a restrição ao direito fundamental atingido.

Entrementes, ao tema proposto a máxima da proporcionalidade será cotejada diante das medidas que podem ser tomadas pela Administração Pública para solucionar as ocupações irregulares nos imóveis públicos, particularmente pela previsão constitucional e legal da concessão de uso especial para fins moradia. Imprescindível, para tal desiderato, uma brevíssima explanação da concessão de uso especial para fins de moradia entre as normas jurídicas brasileiras.

\section{A concessão de uso especial para fins de moradia no Ordenamento Jurídico Brasileiro}

A concessão de uso especial para fins de moradia, instrumento jurídico inaugurado na Constituição Federal 1988 para garantir o direito da população de baixa renda que ocupava assentamentos consolidados em áreas públicas, marca a Política Urbana emergente do Texto Constitucional. Consubstancia-se na regularização fundiária da posse e na promoção da urbanização do local sem recorrer, como de regra, à remoção da população para outras localidades.

Entendeu-se, enfim, que era preciso assegurar e regulamentar o exercício da moradia à população, mercê da transformação da simples posse em concessão de uso (ALFONSIN, 2001, p. 211-212). A regularização da ocupação consolidada garantiria a segurança jurídica da posse, elemento fundamental ao direito de moradia. O Estado, neste mister, passa a adotar normas que garantam o direito de moradia, reconhecendo as diversas formas 
de uso das áreas urbanas. Não seria possível, de fato, alcançar a segurança jurídica sem uma legislação adequada que, no caso da proteção ao direito de moradia através da concessão de uso especial para tal fim, não assegurasse eficácia ao disposto no $\S 1^{\circ}$ do artigo 183 da Constituição Federal. Neste ponto, porém, força reconhecer que o legislador brasileiro ainda não firmou um tratamento jurídico definitivo para o instituto da concessão de uso especial para fins de moradia.

Embora o Estatuto da Cidade (Lei Federal n. 10.257/01), na linha da Constituição Federal, reconheça expressamente o direito dos moradores de ocupações irregulares consolidadas em áreas urbanas públicas a permanecer no local, os artigos 15, 16, 17, 18, 19 e 20 do mesmo diploma legal que regulamentariam aquele instrumento jurídico foram vetados pelo Presidente da República. Verdade que cerca de dois meses depois da publicação do Estatuto da Cidade (e do veto), o Presidente editou a Medida Provisória n. 2.220, de 04 de setembro de 2001. Referida norma, contudo, tanto não foi convertida em lei como permanece em vigor por força do disposto no art. $2^{\circ}$ da Emenda Constitucional n. 32, de 11 de setembro de 2001. Mesmo com a edição da Medida Provisória n. 759, de 22 de dezembro de 2016, posteriormente convertida na Lei 13.465 de 11 de julho de 2017, a Medida Provisória n. 2.220/01 mantem-se vigente.

Assim, a Medida Provisória n. 2.220/2001 ainda disciplina integralmente os requisitos infraconstitucionais da concessão de uso especial para fins de moradia e, em resumo, permite: (i) a concessão de uso especial para fins de moradia ao homem ou mulher que, até 22 de dezembro de 2016, possuía como seu, por cinco anos ininterruptos e sem oposição, até duzentos e cinquenta metros quadrados de imóvel público situado em área com característica e finalidade urbana, desde que o utilize para sua moradia ou de sua família e que não seja proprietário ou concessionário, a qualquer título, de outro imóvel urbano ou rural (art. $1^{\circ}$ ); (ii) a concessão de uso especial para fins de moradia, de forma coletiva, à população de baixa renda que, até 22 de 
dezembro de 2016, possuía como seu, por cinco anos ininterruptos e sem oposição, cuja área total dividida pelo número de possuidores seja inferior a duzentos e cinquenta metros quadrados por possuidor, a concessão de uso especial para fins de moradia será conferida de forma coletiva, desde que os possuidores não sejam proprietários ou concessionários, a qualquer título, de outro imóvel urbano ou rural (art. $2^{\circ}$ ); (iii) a concessão de uso especial para fins de moradia aos ocupantes, regularmente inscritos, de imóveis públicos com até duzentos e cinquenta metros quadrados situados em área urbana (art. $3^{\circ}$ ); e (iv) a concessão de uso especial para fins de moradia, em local distinto, à população de baixa renda que, até 22 de dezembro de 2016, possuía como seu, por cinco anos ininterruptos e sem oposição, até duzentos e cinquenta metros quadrados de imóvel público situado em área com característica e finalidade urbana, desde que não sejam proprietários ou concessionários, a qualquer título, de outro imóvel urbano ou rural (art. $4^{\circ}$ ).

A regulamentação da concessão de uso especial para fins de moradia, como se vê, não trata das situações presentes e futuras, mais precisamente daqueles ocupantes que completarão o período de cinco anos de posse ininterrupta e sem oposição após 22 de dezembro de 2016. A previsão infraconstitucional de uma data limite para a contagem retroativa do prazo dos cinco anos (até 22 de dezembro de 2016), além de esvaziar o conteúdo da garantia constitucional daquele instrumento jurídico, revela a produção de uma norma que não responde às necessidades, aos anseios sociais para as quais foi editada, sendo, portanto, socialmente inútil.

Neste ponto, que o veto presidencial, seguido da edição de Medida Provisória 2.220/2001, com a inserção de prazo prescricional para o exercício do direito, serviu apenas para adiar, indefinidamente, a solução das ocupações irregulares que se consolidarem após 22 de dezembro de 2016. E com essa precariedade jurídica, o Poder Público ficou liberto para negar de implementação de serviços públicos adequados naqueles espaços, além de 
inibir os próprios ocupantes em realizar investimentos em suas residências e nos entornos.

Sem embargo, a opção do constituinte, ao garantir a concessão de uso especial para fins de moradia no imóvel público, se de um lado permite a regularização jurídica da ocupação, de outro não desautoriza ou minimiza a proteção do direito de propriedade do Estado e a própria tutela ambiental.

\section{A Concessão de uso especial para fins de moradia como medida proporcional na solução das ocupações irregulares dos móveis públicos}

Como já dito, as ocupações de imóveis públicos, como faceta dos problemas fundiários que afetam o país, são intercorrentes e presentes na quase totalidade do território. Cuida-se, evidente, de complexo problema de variadas e peculiares características, sejam elas históricas, econômicas, sociais, ambientais e jurídicas, como se dá, de usual, com a regularização fundiária. Aliás, o próprio objeto da ocupação, segundo destinação do imóvel público, revela a impossibilidade de se encetar, genericamente, soluções unívocas, dado que em tese será inadmissível, inclusive, tratar como "posse" a ocupação em relação a alguns, enquanto factível em relação a outros, do que decorre que mesmo os instrumentos jurídicos podem se revelar inadequados.

Assim, se parece intuitivamente desproporcional admitir que os bens de uso comum do povo e os bens de uso especial sejam concedidos aos particulares para que exerçam sobre eles o direito de moradia, o mesmo não se pode referir em relação a totalidade dos bens dominicais. Sobre os bens afetados, ou seja, os de uso comum do povo ou de uso especial, a indisponibilidade transmuda a ocupação indevida em um simples ato de tolerância pelo Estado, considerada então como mera detenção. Mas, os bens dominicais, via de regra, podem ser objeto de posse privada por particulares, pois ausente afetação pública específica. 
Ocupações de bens de uso comum do povo ou de uso especial implicam, por si só, no descumprimento da função social daquela propriedade pública, face a incompatibilidade entre a destinação específica daqueles imóveis com o propósito da moradia dos ocupantes. Em tais hipóteses (ocupações de bens de uso comum do povo ou de uso especial), estima-se que não seria possível aos ocupantes reclamar a concessão de uso especial para fins de moradia no local, uma vez que a afetação do imóvel implica na indisponibilidade da res pública.

Não obstante, como o artigo $5^{\circ}$ da Medida Provisória 2220 de 04 de setembro de 2002 autoriza o Poder Público a conceder o uso especial de moradia em imóvel distinto aos ocupantes que preencherem os requisitos legais e constitucionais, é factível que a pretensão possa ser direcionada a outro local. Estaríamos diante da discricionariedade do administrador em tomar a solução mais adequada. A motivação do ato que determinasse a remoção para concessão em local distinto ou deliberasse pela desafetação, de toda sorte, permitiria a avaliação judicial daquele, uma vez que afetaria tanto o direito de moradia dos ocupantes como o interesse coletivo na utilidade dos bens de uso comum ou de uso especial.

Assim, as soluções possíveis à Administração Pública em tais casos, como dito, seriam a desafetação para regularização fundiária no local (mercê da concessão de uso especial para fins de moradia) ou a desocupação do imóvel público para concessão de uso especial em lugar distinto da ocupação.

Aqui, parece que seja defensável a proteção da propriedade pública como regra, a fim de que o interesse coletivo seja respeitado, ou seja, que somente em hipóteses excepcionalíssimas se admita a desafetação dos bens de uso comum ou especial para fins de regularização fundiária no local da ocupação. A remoção da ocupação consolidada, ainda que hoje não represente a ideologia político-legislativa adotada, em tais hipóteses devem ser considerada como primeira medida, já que aparentemente desproporcional a desafetação. 
É possível, com efeito, avaliar criticamente a desafetação dos bens de uso comum ou de uso especial para fins de regularização fundiária urbana, através do instrumento da concessão de uso especial para fins de moradia. Assim, tomando-se em consideração uma ocupação consolidada de um bem de uso comum (praça ou via pública) ou de uso especial (prédio público ou cemitério), a desafetação daqueles para fins de regularização fundiária no local constituiria medida que coloca em colisão o direito fundamental de propriedade (artigo $5^{\circ}$, caput c/c inciso XXII da Constituição Federal) do Poder Público sobre o imóvel e o direito social de moradia do ocupante (art. $6^{\circ}$, caput, da Constituição Federal). A medida (desafetação) pode então ser mensurada segundo os postulados da máxima da proporcionalidade.

A máxima parcial da adequação (da idoneidade ou da conformidade) determina que se analise a medida em conformidade com a finalidade perseguida. Deve-se examinar se a medida tomada é apta para fomentar ou realizar o objetivo. Como medida preparatória, a desafetação concorre para a regularização da posse, retirando a destinação primitiva do bem, providência que antecede a concessão do título de ocupação e permite futuramente investimentos públicos no local, a par do próprio planejamento urbano.

Estima-se, então, que seja adequada, nos termos exigidos pela máxima da proporcionalidade, tanto para assegurar futuramente a moradia através da regularização fundiária, como para ajustar a finalidade do imóvel. Contudo, deve-se ponderar que a providência aparenta não ser necessária. A máxima parcial da necessidade, de fato, destaca que à medida que limita um direito fundamental só é necessária caso a realização do objetivo não possa ser promovida, com a mesma intensidade, por outro meio que afete, em menor grau, o direito fundamental atingido. Como dito, é inegável que a desafetação do imóvel limita o direito de propriedade do Poder Público, ainda que não ocorra a transferência do domínio pela concessão de uso especial para fins de moradia, pois tolhe a utilidade pública do bem. Porém, existe medida alternativa à desafetação (ou ao pedido de concessão de uso especial no local) 
que pode solucionar a ocupação, tanto para restabelecer o domínio pleno do imóvel ao Poder Público (mercê da desocupação) como assegurar o direito de moradia dos ocupantes.

Preenchidos os requisitos constitucionais e legais para a concessão de uso especial para fins de moradia, nas hipóteses infraconstitucionais insertas no art. $5^{\text {o }}$ da Medida Provisória n. 2220/2001 (como no caso dos bens de uso comum ou de uso especial), o Poder Público pode conceder o uso especial para fins de moradia em outro local, ou seja, a mesma medida (concessão de uso) pode ser tomada de forma distinta para se alcançar a mesma finalidade. Nesse sentido, a desafetação do imóvel público pode não se revelar necessária para regularização fundiária, nos termos da máxima da proporcionalidade, uma vez que a solução da ocupação irregular no imóvel público pode ser buscada através da concessão de uso especial para fins de moradia em local distinto. Cuida-se, enfim, de medida desproporcional.

A constatação, aliás, avulta quando se reconhece factível que alguns bens de uso comum, como os terrenos de praia (artigo 10 da Lei 7.661/88), encerram características ambientais que impõe a preservação e, com isso, a necessária desocupação. Aqui, a própria legalidade, mercê da aplicação das normas que tutelam o meio ambiente, inviabilizariam a proposta de desafetação para fins da concessão de uso especial no local, impondo a desocupação com a concessão em local distinto.

De outro lado, em relação aos bens dominicais, o descumprimento da função social da propriedade pública urbana se dá pela desconformidade com as exigências expostas no Plano Diretor, o que evidentemente pode ser revelada pela própria irregularidade da ocupação. A regularização fundiária no local, então, poderia adequar o imóvel à sua função social, outorgando àquela propriedade urbana uma destinação que atenda às necessidades sociais existentes na cidade. Mas aqui, advirta-se, também a questão ambiental deve ser ponderada com o direito de moradia, a fim de avaliar a concessão de uso especial em local distinto, tal como ocorre com as terras 
devolutas ou arrecadadas pelos Estados, por ações discriminatórias, necessárias à proteção dos ecossistemas naturais, nos termos do $\S 5^{\circ}$ do artigo 225 da Constituição Federal de 1988. Sem embargo, é possível afirmar que os bens imóveis dominicais, em regra, estão sujeitos à regularização fundiária no próprio local da ocupação, face a relevância em se efetivar o direito social de moradia dos ocupantes e adequar o imóvel à função social da propriedade pública.

\section{Considerações Finais}

Em relação aos bens de uso comum e de uso especial, a prévia desafetação do imóvel público pode não se revelar necessária para regularização fundiária, nos termos da máxima da proporcionalidade, uma vez que a solução da ocupação irregular no imóvel público pode ser buscada através da concessão de uso especial para fins de moradia em local distinto. Cuida-se, enfim, de medida desproporcional.

De outro lado, em relação aos bens dominicais, a regularização fundiária no local pode adequar o imóvel à sua função social, outorgando àquela propriedade urbana uma destinação que atenda às necessidades sociais existentes na cidade, revelando-se então como medida que atende à máxima da proporcionalidade.

\section{Referências}

ALFONSIN, Betânia. Políticas de regularização fundiária: justificação, impactos e sustentabilidade. In: FERNANDES, Edésio (org). Direito urbanístico e política urbana no Brasil. Rio de Janeiro: Del Rey, 2001.

ALEXY, Robert. Teoria dos Direitos Fundamentais. Tradução de Virgílio Afonso da Silva. 2. ed. São Paulo: Malheiros, 2011.

ÁVILA. Humberto. Teoria dos princípios: da definição à aplicação dos princípios jurídicos. São Paulo: Malheiros, 2003.

BARROS, Suzana de Toledo. O Princípio da Proporcionalidade e o Controle de Constitucionalidade das Leis Restritivas de Direitos Fundamentais. Ed. Brasília Jurídica, 1996. 
BARROSO, Luís Roberto. Interpretação e aplicação da constituição. 7. ed. São Paulo: Saraiva, 2009.

BONAVIDES, Paulo. Curso de Direito Constitucional. São Paulo: Malheiros. 2006.

CANOTILHO, J. J. Gomes. Direito constitucional e teoria da constituição. 7. ed. Coimbra: Almedina, 2003.

GÓES, Gisele Santos Fernandes. Princípio da Proporcionalidade no Processo Civil: $\mathrm{O}$ poder de criatividade do juiz e o acesso à justiça. São Paulo. Saraiva, 2004.

GUERRA FILHO, Willis Santiago. Princípio da proporcionalidade e o devido processo legal. In SILVA. Virgilio Afonso da (org). Interpretação constitucional. São Paulo: Malheiros, 2005, p. 262.

SILVA. Virgilio Afonso da. O proporcional e o razoável. Revista dos Tribunais, vol. 798. ano 91. abril de 2002.

Artigo recebido em: 03/02/2019.

Aceito para publicação em: 30/04/2020. 